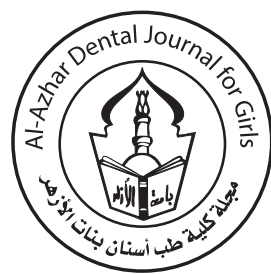

\title{
Fracture Resistance and Retention of Three Different Endocrown Materials
}

\author{
Nada S. Eisa ${ }^{1 *}$, Eman A. Essam², Rania A. Amin ${ }^{3}$, Zainab R. EL Sharkawy
}

Codex : 25/2004

azhardentj@azhar.edu.eg

http://adjg.journals.ekb.eg

DOI: $10.21608 /$ adjg.2020.11248.1135

Restorative Dentistry

(Removable Prosthodontics, Fixed

Prosthodontics, Endodontics, Dental Biomaterials, Operative Dentistry)

\section{KEYWORDS}

Fracture Resistance,

E-max $C A D$, Vita Suprinity,

Vita Enamic.

\begin{abstract}
Purpose: The purpose of the current study was to assess fracture resistance and retention of three different endocrown materials. Materials and Methods: Thirty $(n=30)$ sound mandibular molars were endodontically treated and according to endocrown constructed material appointed arbitrarily into 3 groups ( $\mathrm{n}=10$ each); Group (1): IPS e.max CAD, Group (2): Vita Suprinity and Group (3): Vita Enamic. Samples of each group were additionally subdivided into 2 subgroups ( $n=5$ each) according to fracture resistance and retention tests. Subgroup (A): Samples subjected to fracture resistance test and mode of failure. Subgroup (B): Samples subjected to retention test and mode of failure. The samples were thermocycled and seated on a universal testing machine and subjected to fracture resistance and retention test, then Data were statistically analyzed. Results: The highest mean failure load was recorded for Vita Suprinity endocrowns, followed by IPS e-max endocrowns, while Vita Enamic endocrowns recorded the lowest mean failure load.A non-statistically significant difference between the three tested groups of subgroup (A) revealed by using ANOVA test.The highest debonding load was recorded for Vita Enamic endocrowns, followed by IPS e-max CAD endocrowns, while the lowest mean debonding was recorded for Vita Suprinity endocrowns. A nonstatistically significant difference between the three tested groups of subgroup (B) revealed by using ANOVA test. Conclusions: Endocrowns of Vita Suprinity showed higher mean failure load value compared to endocrowns of E-max CAD and Vita Enamic. While endocrowns of Vita Enamic showed higher mean debonding load value compared to E-max CAD and Vita Suprinity.
\end{abstract}

- Paper extracted from master thesis titled "Fracture Resistance and Retention of Three Different Endocrown Materials"

1. Dentist at ministry of health, Egypt

2. Professor of Fixed Prosthodontics, Faculty of Dental Medicine, Al-Azhar University, Cairo, Egypt.

3. Assistant Professor, Crown and Bridge Department, Faculty of Dental Medicine for Girls, AL-Azhar University, Cairo, Egypt.

4. Lecturer, Crowns and Bridges Department, Faculty of Dental Medicine for Girls, Al Azhar University, , Cairo, Egypt.

* Corresponding author email: dr.nadasameh@gmail.com 


\section{INTRODUCTION}

The common problem in restoration of endodontically treated teeth is the higher risk of biochemical deterioration; which might be attributed to the access cavity preparation that increase the incidence of fracture ${ }^{(1)}$. Therefore, when considering the restoration of such teeth, restorative materials should be capable of replacing the loss of the tooth structure to guarantee mechanical, esthetics, functional properties and coronal seal ${ }^{(2,3)}$.

Post and core with overlying crown considered as a traditional method for restoring endodontically treated teeth. Root canal preparation and the use of post reduces the remaining tooth structure and cause uneven stress distribution along the length of post ${ }^{(4)}$. Using steel posts promoting root fracture even with using less rigid cements to make stress absorbing effect. This might be attributed to the increased stiffness and rigidity of such posts. In 1990s, fiber-reinforced composites post were presented. The fiber-reinforced posts are made of unidirectional, braided or woven fibers, embedded in a resin matrix. These fibers have been utilized to strengthen endodontic posts ${ }^{(5)}$.

Although the use of post will aid in the retention of restoration, it may lead to increase the fracture incidence of the root. Furthermore, preparation of adequate ferrule, fabrication of core and manufacturing of a crown, increasing the treatment cost and time ${ }^{(6)}$. All these intermediate stages may likewise increase bacterial infiltration and cause endodontic reinfection ${ }^{(7)}$.

Restorations bonded to enamel and dentin decrease the need for conventional means of retention regarding taper and height, so that they are especially indicated in situations of minimal or no retention, Furthermore they are less traumatic for the tooth ${ }^{(8,9)}$.
Endocrowns, prescribed as bonded overlay restorations consist of coronal portion and apical projection anchored to the pulp chamber space to achieve macromechanical retention, whereas, micromechanical retention is achieved by the use of adhesive cementation. As the depth of pulp chamber and intracoronal extension increase ${ }^{(10,11)}$, the micromechanical retention and dispersion of masticatory stresses increase ${ }^{(12)}$.

Using endocrown restorations make the restored tooth act as a monoblock, so reduce the effect of numerous restorative interfaces ${ }^{(13)}$. Endocrowns can restore teeth with insufficient vertical dimension, they can restore badly broken down teeth while preserving the maximum tooth structure rendering more efficient and esthetic results ${ }^{(14,15)}$.

The preparation of endocrown was done with 2 $\mathrm{mm}$ intracoronal extension to retain the restoration and to strengthen the remaining tooth structure. The height of the endocrown, the finish line position and the magnitude of the applied force could influence the failure of the endocrown. Therefore, endocrown dimensions were adjusted using the CAD/CAM technology that permitted standardization of the size and shape of restoration and the point of application of load during testing ${ }^{(16)}$. Endocrowns are mandatory in cases of fragile, severely curved, obliterated roots and limited interocclusal space ${ }^{(17,18)}$. Endocrown - related studies revealed adequate functioning and esthetics and a reasonable fracture strength of endocrown restoration ${ }^{(19,20)}$.

Ceramics can be classified in to glass-based ceramic (silica based ceramic), glass-based ceramic with fillers; typically leucite crystals as leucite based ceramic or, lithium disilicate crystals as high strength lithium disilicate glass ceramic, crystalline based ceramic with glass fillers mainly alumina, as (InCeram) and polycrystalline oxide ceramic(alumina and zirconia) ${ }^{(21)}$.

Zirconia reinforced lithium silicate ceramics is a new member in the lithium ceramic family by 
addition of $10 \%$ by weight zirconia to the same basic component. The average size of the fine crystals of zirconia reinforced lithium silicate ceramic is 0.5 $\mathrm{mm}$ whereas, the average size of the the needleshaped crystals in the lithium disilicate ceramic is $1.5 \mathrm{~mm}^{(22)}$.

Hybrid ceramics consist of double interpenetrating networks of ceramic and polymer with a reasonable brittleness index. This type of ceramics combine the characteristics of ceramic and polymers ${ }^{(23)}$.

The current study aimed to assess the fracture resistance and the retention of endocrowns constructed from IPS e.max CAD, Vita Suprinity and Vita Enamic.

\section{MATERIAL AND METHODS}

\section{Preparation of tooth samples:}

Thirty $(\mathrm{n}=30)$ mandibular molars with completed roots, cracks or fracture free, were collected cleaned and saved in saline. To standardize the size of the selected teeth a digital caliper (S235, Sylvac, Switzerland), was used to measure the bucco-lingual and mesio-distal dimensions of each molar at the level of the cemento-enamel junction. Each tooth was fixed vertically in epoxy resin using PVC rings as molds. All teeth were endodontically prepared using rotary files (Dentsply Maillefer, Switzerland) then filled with gutta percha (Dentsply Maillefer, Switzerland). All endodontically treated teeth $(n=30)$ were arbitrary divided in to 3 groups ( $\mathrm{n}=10$ each) according to the sort of material of the constructed endocrown in to Group (1): IPS e.max CAD endocrown, Group (2): Vita suprinity endocrown, Group (3): Vita enamic endocrown. Then each group was subdivided in to 2 subgroups according to testing procedures, subdroup(A): samples were subjected to fracture resistance test and mode of failure determination and subgroup(B): samples were subjected to retention test.

\section{Endocrown Preparation:}

A special milling machine (Centroid CNC, Milling machine, USA), was used for standardized teeth preparations. Teeth were decapitated $3 \mathrm{~mm}$ above the cement enamel junction (CEJ) perpendicular to the long axis of the tooth. The endodontic access cavities were prepared with diamond stone ((Dentsply Maillefer, Switzerland) with $8^{0}-10^{0}$ coronal divergence, the depth of the central retention cavity measured $4.5 \pm 0.5 \mathrm{~mm}$ from decapitation level. Extracoronally, the remaining vertical portion of the crown was prepared with diamond stone (DentsplyMaillefer, Switzerland). The preparation included a $1 \mathrm{~mm}$ wide, circumferential $90^{\circ}$ shoulder margin with rounded internal line angles, located $1 \mathrm{~mm}$ above the cement enamel junction leaving a $2 \mathrm{~mm}$ ferrule. The external convergence angle was adjusted at $8^{\circ}-10^{\circ}$. The remaining thickness of dentin walls $(2 \pm 0.5 \mathrm{~mm})$ was measured by digital caliper.

\section{Laboratory procedures:}

The prepared tooth was sprayed with anoptical reflection powder (Ceramill Scanmarker, Amann Girrbach AG, Austaria) and scanned using Ceramill scanner (Ceramill map 400, Amann Girrbach AG, Austaria). Thesoftware (Ceramill mind, Amann Girrbach AG, Austaria) design a virtual model from the scanned picture. The restorations were designed and fabricated with CAD/CAM milling machine (Ceramill motion 2, Amann Girrbach AG, Austaria) using IPS e.max CAD/CAM blocks (Ivocalr Vivadent, Germany), Vita Suprinity blocks (Vita Zahnfabric , Bad Sackingen, Germany) and Vita Enamic blocks(Vita Zahnfabric , Bad Sackingen, Germany). The milled bluish partially crystallized IPS e.max CAD restorations were polished using OptraFine(Ivoclar vivadent AG,Lichenstien, Germany) then Crystallization was done according to manufacturer's instruction using Programat furnace (P300). Crystallization of Vita Suprinity was done according to manufacturer's instruction, using 
Vita vacumat furnaces. Samples of Vita Suprinity and Vita Enamic were polished using Vita Suprinity Polishing kit (Vita Zahnfabric, Bad Sackingen, Germany) and Vita Enamic Polishing kit (Vita Zahnfabric, Bad Sackingen, Germany) respectively according to the manufacruter's instructions with no additional glaze firing.

\section{Bonding procedure:}

\section{Restoration surface treatment:}

The internal surfaces endocrowns were etched with 5\% hydrofluoric acid (BISCO, Inc. $1100 \mathrm{~W}$. Irving Park Rood Schumburg, IL 60193. USA) applied for 20, 20, 60 seconds for group (1,2 and $3)$ respectively. After etching, each restoration was cleaned for five minute sultrasonically with water, then dried with oil-free air. Silane coupling agent (BISCO, Inc. 1100 W. Irving Park Rood Schumburg, IL 60193. USA) was applied to the intaglio surface for 60 seconds and then air dried.

\section{Tooth surface treatment:}

$32 \%$ phosphoric acid etching gel (3M ESPE, St Paul, MN, USA) was applied for 15 seconds to the cleaned and dried bonding surfaces with syringe tip. A thin layer of light-cured bonding agent ((3M ESPE, St Paul, MN, USA), was applied to bonding surfaces, a gentle steam of air was blowed over the liquid for 5 seconds then was light cured for 10 seconds.

\section{Adhesive procedure:}

A double dosage of 1:1 base-to-catalyst ratio mixed into a homogenous mix for 20 seconds. The mix was applied on the fitting surface of the restoration and prepared tooth surface. The restoration was seated on the tooth under finger pressure and excess cement was removed. Then the sample was placed under $3 \mathrm{~kg}$ weight in the load applicator, then cement was light cured for 20 seconds per surface.

\section{Thermal cycling:}

All samples were subjected to a thermocycling procedure in automated thermocycling machine. Samples were thermocycled for 2000 cycle, between $5^{\circ} \mathrm{C}-55^{\circ} \mathrm{C}$, with a dwell time 25 seconds.

\section{Testing procedures:}

\section{Fracture resistance determination:}

Each sample was individually mounted to the lower compartment of a universal testing machine (LRX-Plus, Lloyd Instruments, UK) and subjected to a static increasing compressive load $(1 \mathrm{~mm} /$ min) applied vertically to the occlusal surface until fracture. Fracture loads were recorded in Newton.

\section{Fracture mode analysis:}

Fractured samples were examined to determine the type of fracture using magnification lens (Mars, Japan.) (X=15) and environmental scanning electron microscope (SEM- Quanta FEG -250, ESEM., FEI Company, Netherlands.).

\section{Retention test: (Debonding load determination):}

Each sample was individually mounted to the lower compartment of a universal testing machine (LRX-Plus, Lloyd Instruments, UK) while each restoration was connected to the upper movable compartment of the testing machine by orthodontic wire loop through the lateral projections of the restoration. A tensile load with pull out mode of force was applied via the machine at a crosshead speed of $5 \mathrm{~mm} / \mathrm{min}$. The load required for debonding was recorded in Newton.

\section{Statistical analysis:}

Statistical analysis was performed with SPSS 16.0 (Statistical Package for Scientific Studies,Inc., , USA). Two ways analysis of variance (ANOVA) test was used for comparisons between all subgroups. 


\section{RESULTS}

\section{Fracture resistance test:}

The highest mean failure load was recorded for Vita Suprinity endocrowns (subgroup(A),g $\operatorname{roup}(2)) ;(1309.85 \pm 332.92 \mathrm{~N})$ followed by IPS e-max endocrowns (subgroup(A),group(1)); $(1088.33 \pm 151.72 \mathrm{~N})$. While Vita Enamic endocrowns (subgroup (A), group (3)) recorded the lowest mean failure load); (1020.45 $\pm 211.35 \mathrm{~N})$. Statistical analysis using ANOVA test revealed a non-significant difference among the three tested groups at $(\mathrm{P}<0.05)$ Values are presented numerically in table (1).

Table (1): The P-value (ANOVA test) for the mean failure loads $(N)$ of the three tested subgroups

\begin{tabular}{|c|c|c|c|}
\hline subgroups & $\begin{array}{c}\text { Subgroup(A) } \\
\text { Group (1) } \\
\text { IPS e-max } \\
\text { CAD } \\
\text { endocrowns }\end{array}$ & $\begin{array}{c}\text { Subgroup(A) } \\
\text { Group (2) } \\
\text { Vita } \\
\text { Suprinity } \\
\text { endocrowns }\end{array}$ & $\begin{array}{c}\text { Subgroup(A) } \\
\text { Group (3) } \\
\text { Vita Enamic } \\
\text { Endocrowns }\end{array}$ \\
\hline $\begin{array}{c}\text { No of } \\
\text { samples }\end{array}$ & 5 & 5 & 5 \\
\hline Mean (N) & 1088.5 & 1309.85 & 1020.45 \\
\hline SD & 151.72 & 332.92 & 211.35 \\
\hline P-value & \multicolumn{3}{|c}{$0.3631^{\mathrm{ns}}$} \\
\hline
\end{tabular}

$n s=$ non-significant at $P<0.05$

\section{Analysis of fracture mode:}

On examination of fractured samples, it was clearly observed that most samples fractures occurred within both restoration and the tooth structure. Most tooth fractures occurred below the level of simulated bone (epoxy resin) indicating irreparable type of fracture (Type IV, catastrophic fracture), figure $(1,2,3)$. Two samples from subgroup(A) group(3) were fractured above the level of the simulated bone (Type III, acceptable fracture), figure $(4,5)$, None of the tested samples showed type I or II.

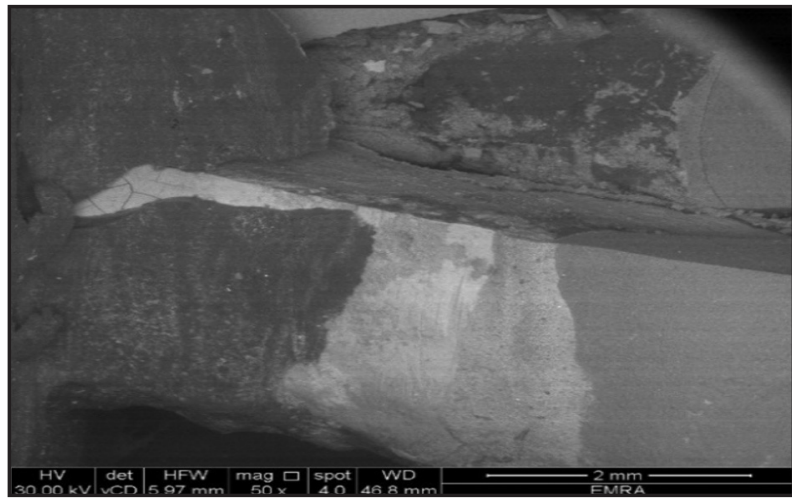

Figure(1) SEM photographs of type IV fracture (arrow) in; subgroup (A), group (1) (Original magnification X50)

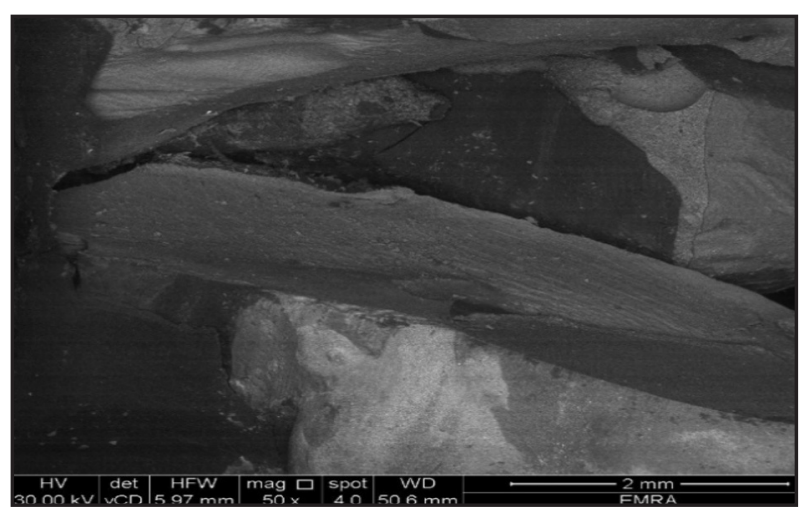

Figure(2) SEM photographs of type IV fracture (arrow) in; subgroup (A), group (2) (Original magnification X50)

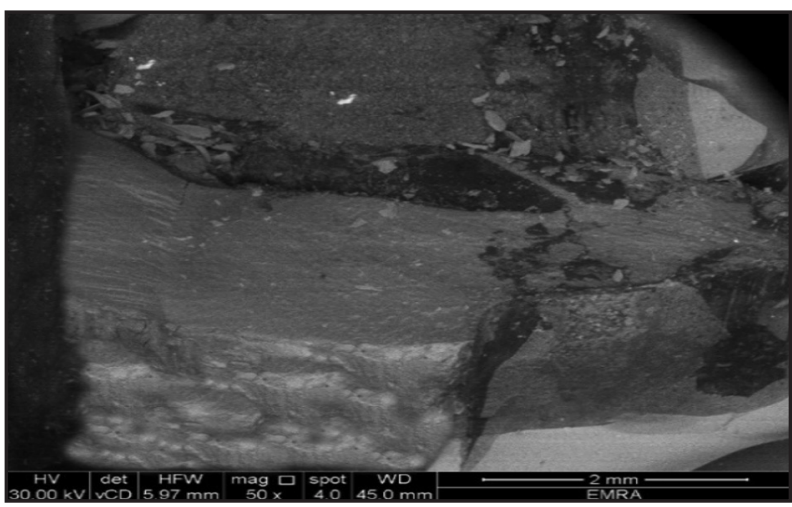

Figure(3) SEM photographs of type IV fracture (arrow) in; subgroup (A), group (3). (Original magnification X50) 


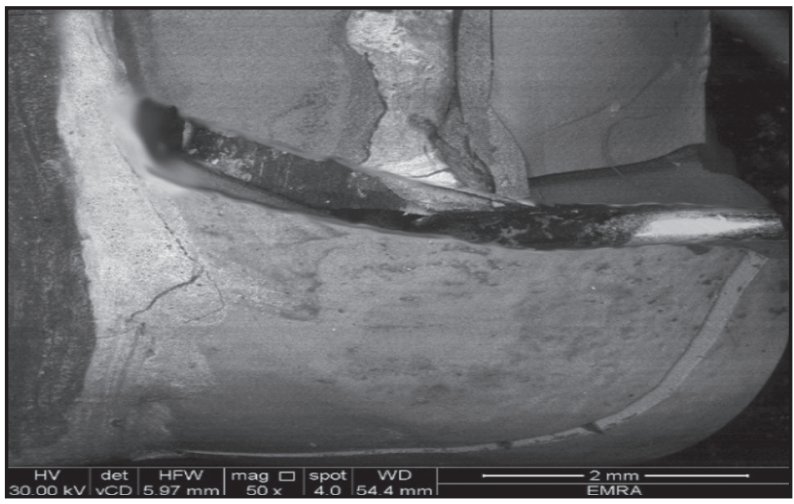

Figure(4) SEM photographs of type III fracture (arrow) in : subgroup (A), group(3) . (Original magnification X50)

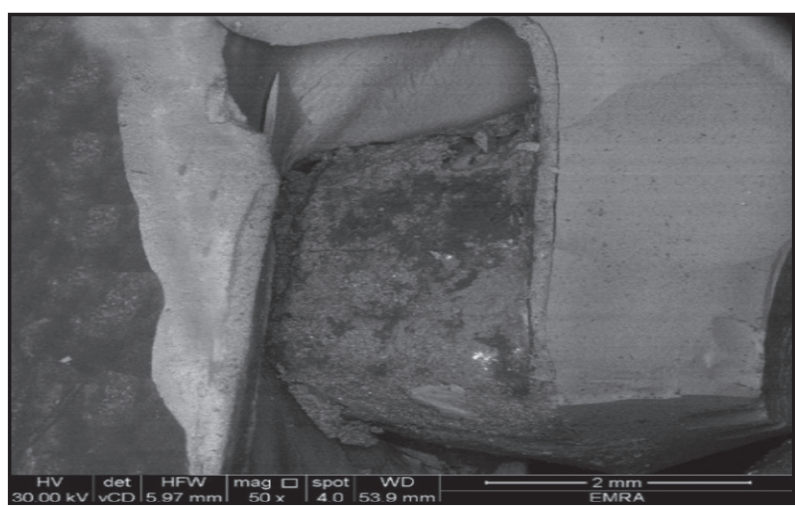

Figure(5) SEM photographs of type III fracture (arrow) in: subgroup (A), group (3). (Original magnification X50)

\section{Retention test:}

The highest debonding load was recorded for Vita Enamic endocrowns (subgroup (B), group (3)); $(186.83 \pm 35.85 \mathrm{~N})$ followed by IPS e-max CAD endocrowns (subgroup (B), group (1)); $(184.67 \pm 21.76 \mathrm{~N})$ while the lowest mean debonding was recorded for Vita Suprinity endocrowns (subgroup (B), group (2)); (168.76 $\pm 29.43 \mathrm{~N}$ ).

Statistical analysis using ANOVA test revealed a non-significant difference among the three tested groups at $(\mathrm{P}<0.05)$.Values were presented numerically in table (2).
Table (2): the P-value (ANOVA) for the mean debonding loads $(N)$ of the three tested subgroups

\begin{tabular}{|c|c|c|c|}
\hline Subgroups & $\begin{array}{c}\text { Subgroup(A) } \\
\text { Group (1) } \\
\text { IPS e-max } \\
\text { CAD } \\
\text { endocrowns }\end{array}$ & $\begin{array}{c}\text { Subgroup(A) } \\
\text { Group (2) } \\
\text { Vita } \\
\text { Suprinity } \\
\text { endocrowns }\end{array}$ & $\begin{array}{c}\text { Subgroup(A) } \\
\text { Group (3) } \\
\text { Vita Enamic } \\
\text { endocrowns }\end{array}$ \\
\hline $\begin{array}{c}\text { No of } \\
\text { samples }\end{array}$ & 5 & 5 & 5 \\
\hline Mean (N) & 184.67 & 168.76 & 186.83 \\
\hline SD & 21.76 & 29.43 & 35.85 \\
\hline P-value & \multicolumn{3}{|c}{$0.5871 \mathrm{~ns}$} \\
\hline
\end{tabular}

ns= non-significant at $P<0.05$

\section{Analysis of retention mode of failure}

All endocrowns of (subgroup (B), group (1)) and (subgroup (B), group (3)) were debonded showing remnants of cement on both the endocrowns and internal wall of tooth preparation (type A, cohesive failure within cement), meanwhile, endocrowns of (subgroup (B), group (2)) were dobonded showing remnants of cement only on internal wall of tooth preparation (type $\mathrm{C}$, adhesive failure at restorationcement interface).

\section{DISCUSSION}

Although the use of post and core with placement of crown has been the classical approach for restoring endodontically treated teeth, this rationale has changed as adhesive dentistry initiated the concept of tooth conservation ${ }^{(24)}$. Based on adhesive dentistry, the line of treatment for endodontically treated teeth has been shifted to a decay oriented design concept which include a more conservative restoration depends in its retention on adhesion ${ }^{(25,26)}$.

Therefore, the main interest of the present study was directed towards evaluating the fracture resistance and retention of endocrowns milled from three different CAD/CAM materials; IPS e-max CAD, Vita Suprinity and Vita Enamic, cemented 
with same adhesive approach. Regarding the fracture resistance, the result of the present study revealed a non-statistically significant difference in the fracture load value between the three tested groups of subgroup (A). However, the highest mean fracture load value was recorded with Vita Suprinity followed by IPS e.max CAD and Vita Enamic endocrowns respectively.

This was in agreement with other in-vitro studies ${ }^{(27,28)}$, which observed higher fracture load for Vita Suprinity and IPS e-max CAD compared to Vita Enamic. The higher mechanical properties of lithium disilicate ceramic related to the increased number of interlocking needle like microstructural lithium disilicate crystals which are embedded in the glassy matrix of this ceramic ${ }^{(29)}$. Regarding Vita Suprinity, dissolving $10 \%$ of zirconia in the glassy matrix of lithium silicate ceramics result in higher mechanical and optical properties ${ }^{(30)}$.

Regarding Vita Enamic, the fracture load value obtained in the present study is comparable to IPS e-max CAD and Vita Suprinity which have much higher flexural strength. The flexural strength of Vita Enamic is $150-160 \mathrm{MPa}^{(31)}$, IPS e-max CAD is $360 \mathrm{MPa}^{(32)}$, and for Vita Suprinity is $420 \mathrm{MPa}^{(33)}$. Therefore, the low flexural strength does not always mean low fracture resistance ${ }^{(28)}$. The suggested explanation is reasonable resilience and modulus of elasticity of Vita Enamic to that of natural dentition. In addition, the presence of the polymer network within the ceramic system, which increase the resistance to crack formation and propagation ${ }^{(28)}$.

However, other in-vitro study ${ }^{(34)}$, reported contradictory results to those of the present study; the authors concluded that the fracture resistance of Vita Enamic was higher than Vita Suprinity and IPS e-max CAD ceramics.

On examination of the fracture mode of different studied subgroups, it was found that the fracture was almost typical in all samples of the three tested groups (type IV catastrophic failure) except two samples from Vita Enamic endocrowns showed (type III failure).

The same results were obtained in in-vitro studies ${ }^{(35,36)}$, that revealed a high prevalence of catastrophic fracture in IPS e-max CAD endocrowns. This can be related to the elasticity moduli that affect the susceptibility of ceramic restorative materials to fracture; rigid materials with different modulus of elasticity, such as lithium disilicate (95 GPa) ${ }^{(32)}$, produce stress concentrations that might cause catastrophic failures at critical areas, whereas the more resilient materials with comparable modulus of elasticity to that of the natural dentition distribute stresses under load more uniformly.

In addition, the result of this study showed predominance of (type IV) catastrophic failure in Vita Suprinity endocrowns. This was in agreement with in-vitro biomechanical study ${ }^{(37)}$, which revealed that all teeth restored with Vita Suprinity endocrowns were recorded as non-restorable mode of failure This might be due to the increased modulus of elasticity of Vita Suprinity (70 GPa) ${ }^{(33)}$, compared to dentin (18.6 GPa).

Regarding Vita Enamic mode of fracture, the result of this study is in agreement with another in-vitro study ${ }^{(38)}$, which revealed that catastrophic failures was the most common failure mode of Vita Enamic endocrowns. However, two samples showed acceptable type of fracture (type III), above the level of simulated bone. This might be due to the reasonable modulus of elasticity of Vita Enamic $(30 \mathrm{GPa})^{(31)}$, to that of the natural dentition. In addition, the interpenetrating networks of ceramic and polymer which increase the resistance to crack formation and propagation.

Regarding the retention, the result of the current study showed non-statistically significant difference in retention between the three tested groups of subgroup (B). However the highest mean debonding load value was recorded with Vita Enamic endocrowns followed by IPS e-max CAD and Vita Suprinity endocrowns respectively. 
This was in agreement with in-vitro studies ${ }^{(39,40)}$, which concluded that the bond strength results could be affected by the difference in the elasticity moduli,Vita Enamic obtained higher micro tensile bond strength values, the modulus of elasticity of Vita Enamic is $(30 \mathrm{GPa})^{(31)}$, which is comparable to that of dentin (16 - 20.3 GPa)and lower than IPS e-max $(95 \mathrm{GPa})^{(32)}$, and Vita Suprinity $(70 \mathrm{GPa})^{(33)}$. Furthermore, the copolymerization process which occur between the $14 \%$ resin and methacrylate monomers with acidic group present in Rely $\mathrm{X}$ Ultimate cement resulting in the higher microtensile bond strength values of Vita Enamic ${ }^{(41,42)}$.

The lower microtensile bond strength values of IPs e-max and Vita Suprinity could be related to the higher modulus of elasticity of these materials, the more rigid materials generate stresses at the bonding interfaces leading to lower bond strength than the more resilient material ${ }^{(43-45)}$.

Moreover, the lowest retention value of Vita Suprinity in the present study could be explained by an in-vitro study ${ }^{(46)}$, which reported that modifying and treating the zirconia surface by acid etching and silane application was ineffective because of the reduction in the glassy matrix and Si content of Vita suprinity by $\mathrm{ZrO} 2$ addition in an attempt to increase the mechanical properties ${ }^{(47-49)}$.

On examination of the retention failure mode of different studied groups, it was found that endocrowns of IPS e.max CAD and Vita Enamic showed cohesive failure of cement, type (A) failure, as remnants of cement was detected on both restoration and tooth. On the other hand, endocrowns of Vita Suprinity showed predominance of adhesive failure type (C) between resin and restoration. Predomination of cohesive failure in IPS e.max CAD and Vita Enamic prove that bonding of cement to the surface of tooth structure and restoration exceeds the inherent strength of the cement itself, also the surface treatment of the tooth structure improved bonding with the cement so, no adhesive failure occurred.
This was found in agreement with an invitro study ${ }^{(39)}$, which reported that Vita Enamic surface treatment dissolve the glassy matrix and create a honeycomb-like surface rough and micromechanically retentive. This can explain the high percentage of cohesive failure of cement for Vita Enamic luted with RelyX Ultimate resin cement $^{(50,51)}$.

Meanwhile Vita Suprinity surface treatment create narrow craters and pits resulting in nearly smooth surface, which might be due to the densely packed fine crystals in the microstructure of Vita Suprinity. This can explain the predominance of adhesive failure between Vita suprinity and RelyX Ultimate resin cement ${ }^{(52-54)}$.

In another study ${ }^{(55)}$, it was found that there was no adhesive failure at the ceramic-cement interface for IPS e.max CAD. This might be due to the excellent micromechanical retention between the ceramic surface of IPS e.max CAD and cement after hydrofluoric acid etching as well as chemical bonding after silane application.

\section{CONCLUSIONS}

Within the limitations of the present study and for the tested materials, it was concluded that:

1. All obtained fracture resistance and retention values lie within the clinically acceptable ranges.

2. The rational of restoring endodontically treated teeth can be extended to include IPS e-max as well as Vita Suprinity and Vita Enamic endocrowns.

3. Higher fracture resistance values can be obtained with Vita Suprinity endocrowns compared to IPS e-max and Vita Enamic endocrowns.

4. Higher debonding load value can be obtained with Vita Enamic endocrowns, compared to IPS e-max and Vita Suprinity endocrowns. 


\section{REFERENCES}

1. Schwartz RS, Robbins JW.Post placement and restoration of endo dontically treated teeth: a literature review. J Endod . 2004; 30:415 289-301.

2. Veselinovi V, Todorovi A, Lisjak D. Restoring endodontically treated teeth with all-ceramic endo-crowns: case report. Stomatol Glas Srb . 2008; 55:54-64.

3. Da Rosa Rodolpho PA, Cenci MS, Donassollo TA. A clinical evaluation of posterior composite restorations: 17-year findings. J Dent. 2006; 34:427-35.

4. Heydecke G, Butz F, Strub JR. Fracture strength and survival rate of endodontically treated maxillary incisors with approximal cavities after restoration with different post and core systems: an in vitro study. J Dent.2001; 29:427-33.

5. Lanza A, Aversa R, Rengo S, Apicella D, Apicella A. 3D FEA of cemented steel, glass and carbon posts in a maxillary incisors. Dent Mater. 2005; 21:709-15.

6. El-Damanhoury HM, Haj-Ali RN, Platt JA. Fracture Resistance and Microleakage of Endocrowns Utilizing Three CAD-CAM Blocks. Oper Dent. 2015, 40-1.

7. Isidor F, Ödman P, Brøndum K. Intermittent loading of teeth restored using prefabricated carbon fiber posts. Int $\mathrm{J}$ Prosthodont 2000; 9:131-7.

8. Conrad HJ, Seong WJ, Pesun IJ. Current ceramic materials and systems with clinical recommendations: A systematic review. J Prosthet Dent. 2007; 98:389-404.

9. Manicone PF, Rossi Iommetti P, Raffaelli L. An overview of zirconia ceramics: Basic properties and clinical applications. J Dent. 2007; 35:819-26.

10. Sevimli G, Cengiz S, Oruc S. Endocrowns: review. J Istanbul Univ Fac Dent 2015; 49:57-63.

11. Biacchi GR and Basting RT, "Comparison of fracture strength of endocrowns and glass fiber post-retained conventional crowns, Oper Dent. 2012; 37:130-6.

12. Rocca GT, Rizcalla N, and Krejci I, "Fiber-reinforced resin coating for endocrown preparations: a technical report," Oper Dent. 2013; 38: 242-8.

13. Skalyskyi V, Makeev V, Stankevych O. Features of fracture of prosthetic tooth-endocrownconstructions by means of acoustic emission analysis. Dent Mater. 2018; 34: 46-55.

14. Cormier CT, Burns DR, Moon P. In vitro comparison of the fracture resistance and failure mode of fibre, ceramic, and conventional post systems at various stages of restoration. J Prosthodont 2001; 10: 26-36.
15. Maccari PC, Conceicao EN, Nunes MF. Fracture resistance of endodontically treated teeth restored with three different prefabricated aesthetic posts. J Esthet Restor Dent 2003; 15: 25-30.

16. Aboushelib MN, Kleverlaan CJ, Feilzer AJ. Selective infiltration-etching technique for a strong and durable bond of resin cements to zirconia-based materials. J Prosthet Dent 2007; 98: 379-88.

17. Biacchi GR, Mello B, Basting RT. The endocrown: an alternative approach for restoring extensively damaged molars. J Esthet Restor Dent. 2013; 25: 383-90.

18. Ramirez-Sebastia A, Bortolotto T, Cattani-Lorente M, Roig M, Krejci I. Adhesive restoration of anterior endodonticallytreated teeth: influence of post length on fracture strength. Clin Oral Investig. 2014; 18: 545-54.

19. Magne P, Carvalho A, Bruzi G, Anderson RE, Maia HP, Giannini M. Influence of no-ferrule and no-post buildup design on the fatigue resistance of endodontically treated molars restored with resin nanoceramic CAD/CAM crowns. Oper Dent 2014; 39: 595-602.

20. Lander E, Dietschi D. Endocrowns: a clinical report. Quintessence Int 2008; 39: 99-106.

21. Edward A, McLaren DS, Tran CP.DDS Ceramics in Dentistry-Part I: Classes of Materials. Inside dentistry. 2009 .

22. Lien W, Roberts HW, Platt JA .Microstructural evolution and physical behavior of a lithium silicate glass-ceramic. Dent Mater. 2015;31:928-40.

23. 23. Dirxen C, Blunck U, Preissner S.Clinical performance of a new bio-mimetic double network material. Open Dent J. 2013;7:118-22.

24. Pissis P. Fabrication of metal-free ceramic restoration utilizing the monoblock technique. Pract Periodontics Aesthet Dent 1995; 7:83-94.

25. Ausiello P, Rengo S, Davidson CL, and Watts DC. Stress distributions in adhesively cemented ceramic and resin composite Class II inlay restorations: A 3D-FEA. Dent Mater;2004; 20:862-72.

26. Otto T. Computer-Aided direct all-ceramic crowns; preliminary 1-year results of a prospective clinical study. Int J Periodontics Restorative Dent.2004;24:446-55.

27. Al- Akhali M, Chaar M, Elsayed A, Samran A, Kern M. Fracture resistance of ceramic and polymer-based occlusal veneer restorations. J Mech Behav Biomed Mater.2017; 74: 245-50. 
28. Taha D, Spintzyk S, Sabet A, Wahsh M, Salah T. Assessment of marginal adaptation and fracture resistance of endocrown restorations utilizing different machinable blocks3 subjected to thermomechanical aging. J Esthet Restor Dent.2018; 30:319-28.

29. Oh, S.C., Dong, J.K., Luthy, and H. Strength and microstructure of IPS Empress 2 glass-ceramic after different treatments.Int .J.Prosthdodont. 2000; 13:468-72.

30. Elsaka, S.E., Elnaghy, A.M.,. Mechanical properties of zirconia reinforced lithium silicate glass-ceramic. Dent. Mater. 2016: 32, 908-14.

31. Vita Enamic. Techniqual and scientific documentation. VITA Zahnfabrik, Bad Sackingen, Germany, 2013: 8-13.

32. Ivoclar Vivadent technical .IPS E.max CAD:Instructions for use chair side 2009.

33. Vita suprinity: Techniqual and scientific documentation. VITA Zahnfabrik, Bad Sackingen, Germany, 2014, 5.

34. Yildirim G. Fracture Resistance of CAD-CAM Ceramic Crowns: An in vitro Analysis. SF Dent Oral Res J. 2017; $1: 1-7$

35. El-Damanhoury HM, Haj-Ali RN, and Platt JA. Fracture resistance and microleakage of endocrowns utilizing three CAD-CAM blocks .Oper Den. 2015; 40:201-10.

36. Biacchi GR, and Bastingg RT. The endocrown: an alternative approach for restoring extensively damageg molars. J Esthet Restor Dent.2012; 9:383-90.

37. Aktas G, Yerlikaya H, and Akca K. Mechanical failure of endocrowns manufactured with different ceramic materials: An in vitro biomechanical study. J Prosthodont 2018; 340-46.

38. Taha D, Spintzyk S, Schille C, Sabet A, Marwa Wahsh $\mathrm{M}$, and Salah T. Fracture resistance and failure modes of polymer infiltrated ceramic endocrown restorations with variations in margin design and occlusal thickness. J Prosthodont Res.2017; 443; 1-6.

39. Bellan MC ,Jerzeweki PF, Cunha SD, Tavares JG, Spohr $\mathrm{AM}$, and Mota AG. Microtensile bond strength of CAD/ CAM materials to dentin under different adhesive strategies. Braz. Oral Res. 2017; 31: 109.

40. El-saeed SA, Mohamed IT, Eltayeb HE. Comparative Study between Resin Nano Ceramic and CAD/CAM Ceramic Regarding Their Fracture Resistance, Microtensile Bond Strength and Fatigue Resistance. ADJ-for Girls. January 2018; 5: 55:63

41. El Zohairy AA, De Gee J. Microtensile bond strength testing of luting cements to prefabricated CAD/CAM ceramic and composite blocks. Dent Mater 2003; 19:575-83.

42. Dos Santos VH, Griza S, de Moraes RR, Faria-E-Silva AL. Bond strength of self-adhesive resin cements to composite submitted to different surface pretreatments. Restor Dent Endod 2014; 39: 12-6.

43. Homaei E, Farhangdoost K, Tsoi JK, Matinlinna JP, Pow $\mathrm{EH}$. Static and fatigue mechanical behavior of three dental CAD/CAM ceramics.J Mech Behav Biomed Mater. 2016;59:304-13

44. Coldea A, Swain MV, Thiel N. Mechanical properties of polymer-infiltrated-ceramic-network materials. Dent Mater. 2013 Apr; 29:419:26.

45. Elsaka SE, Elnaghy AM. Mechanical properties of zirconia reinforced lithium silicate glass-ceramic. Dent Mater. 2016; 32:908-14.

46. Mattiello RD, Coelho TM, Insaurralde E, Coelho AA, Terra GP and Kasuya AVB. A Review of Surface Treatment Methods to Improve the Adhesive Cementation of ZirconiaBased Ceramics. ISRN Biomaterials. August 2013; 1-10.

47. Kitayama S, Nikaido T, Takahashi R. Effect of primer treatment on bonding of resin cements to zirconia ceramic. Dent Mater. 2010; 26: 426-32.

48. Takeuchi K, Fujishima A, Manabe A, "Combination treatment of tribochemical treatment and phosphoric acid ester monomer of zirconia ceramics enhances the bonding durability of resin-based luting cements," Dent Mater J.2010; 29:316-23.

49. Torres SMP, Borges GA, Spohr AM, Cury AADP, Yadav $\mathrm{S}$, and Platt JA, "The effect of surface treatments on the micro-shear bond strength of a resin luting agent and four all ceramic systems," Oper Dent.2009;34: 399-407.

50. Jardel V, Degrange M, Picard B, Derrien G. Surface energy of etched ceramic. Int J Prosthodont. 2005; 12:415-8.

51. Venturini AB, Prochnow C, Rambo D, Gundel A, Valandro LF. Effect of hydrofluoric acid concentration on resin adhesion to a feldspathic ceramic. J Adhes Dent. 2015; $17: 313-20$

52. Hu M, Weiger R, Fischer J. Comparison of two test designs for evaluating the shear bond strength of resin composite cements. Dent Mater. 2016; 32:223-32.

53. Lung CY, Matinlinna JP. Aspects of silane coupling agents and surface conditioning in dentistry: an overview. Dent Mater. 2012; 28:467-77.

54. Özcan M, Volpato CA. Surface conditioning protocol for the adhesion of resin-based materials to glassy matrix ceramics: how to condition and why? J Adhes Dent. 2015; 17:292-3

55. Bahgat SF, Basheer RR, El sayed FM. Effect of zirconia addition to lithium disilicate ceramic on translucency and bond strength using different adhesive strategies.E.D.J 2015; 61:4519- 33 . 